\title{
Intraoperative analysis of cross-talk inhibition between diaphragmatic and cardiac pacemakers
}

\author{
Katrina Fernandes, ${ }^{1}$ Ruth Louise McLeod, ${ }^{1}$ Mehrdad Nikfarjam, ${ }^{2}$ \\ Laurence Weinberg ${ }^{3,4}$
}

${ }^{1}$ Faculty of Medicine, Nursing and Health Sciences, Monash University, Melbourne, Victoria, Australia

${ }^{2}$ Department of Surgery, Austin Hospital, Melbourne, Victoria, Australia

${ }^{3}$ Department of Anaesthesia, Austin Hospital, Heidelberg, Victoria, Australia

${ }^{4}$ Department of Surgery and Anaesthesia Perioperative Pain Medicine Unit, University of Melbourne, Melbourne, Victoria, Australia

\section{Correspondence to}

Associate Professor Laurence Weinberg, laurence.weinberg@ austin.org.au

Accepted 14 January 2016

\section{DESCRIPTION}

Diaphragmatic pacing is advocated in select patients with ventilatory failure due to weakness or paralysis of the diaphragm to eliminate or reduce the need for ventilatory support and to enhance quality of life. In our case, a 65-year-old ventilator-dependent tetraplegic male underwent diaphragmatic pacing with a NeuRx Diaphragm Pacing System (DPS) (Synapse Biomedical, USA) after sustaining a complete C1 spinal fracture. Prior to surgery, the patient required a dual chamber (right atrium and right ventricular apex) permanent cardiac pacemaker (Versa, Medronics, USA) for episodes of asystole. A limitation of right ventricular (RV) apical pacing is far-field $\mathrm{R}$-wave oversensing, that is, processing of signals originating from myopotentials from nearby muscular structures such as the diaphragm, ${ }^{1}$ which can result in either inappropriate inhibition of pacing, or overcounting of ventricular or atrial events. Therefore, when positioning the cardiac pacemaker we carefully explored several locations to find an optimal site for the RV lead without stimulating the diaphragm or causing diaphragmatic myopotential.

As the DPS does not have a sensing component, it was also important to determine whether there would be any interaction or interference between the two pacemaker systems, otherwise known as 'cross-talk inhibition'. ${ }^{2}$ During laparoscopic insertion of the DPS, neuromuscular blocking agents were avoided. Testing of 'cross-talk inhibition' was performed with the cardiac pacemaker set to maximum sensitivity $(0.5 \mathrm{mV})$, and the

\section{Learning points}

- Right ventricular septal pacing is an alternative site to consider if conventional RV apical pacing is limited by far-field R-wave oversensing, that is, processing signals originating from myopotentials from nearby muscular structures such as the diaphragm.

- Diaphragmatic pacing commonly causes electrical interference in surface ECGs, which can interfere with cardiac pacemaker function. Interference between diaphragmatic pacing and cardiac pacemakers is known as 'cross-talk inhibition'.

- Intraoperative analysis of 'cross-talk inhibition' should be determined by direct interrogation of the cardiac pacemaker.

- Permanent cardiac pacemakers are not a contraindication for the implantation of diaphragmatic pacing systems in select ventilator-dependent patients.

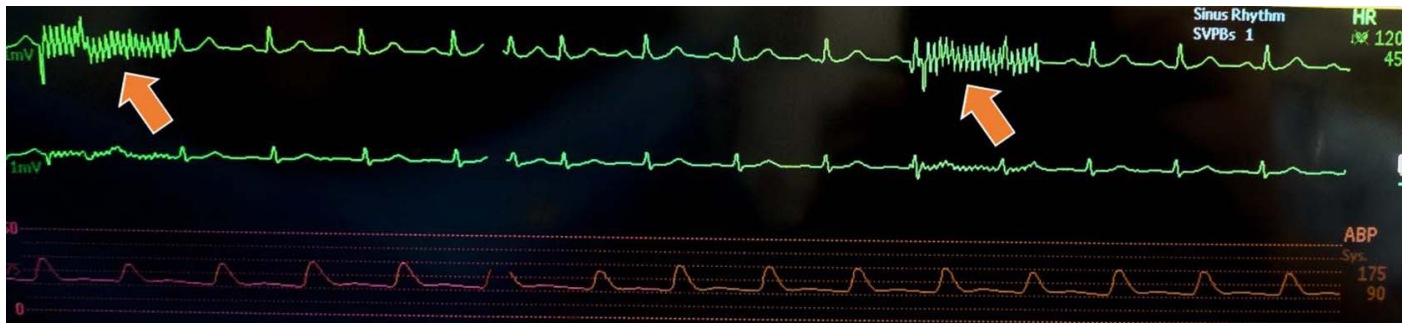

Figure 1 Intraoperative continuous surface ECG recording demonstrating sinus rhythm with electrical interference shown as high-frequency oscillations (arrows), during repetitive pacing of the diaphragm.

\section{(1) CrossMark}

To cite: Fernandes $\mathrm{K}$, Mcleod RL, Nikfarjam M, et al. BMJ Case Rep Published online: [please include Day Month Year] doi:10.1136/bcr-2015213992

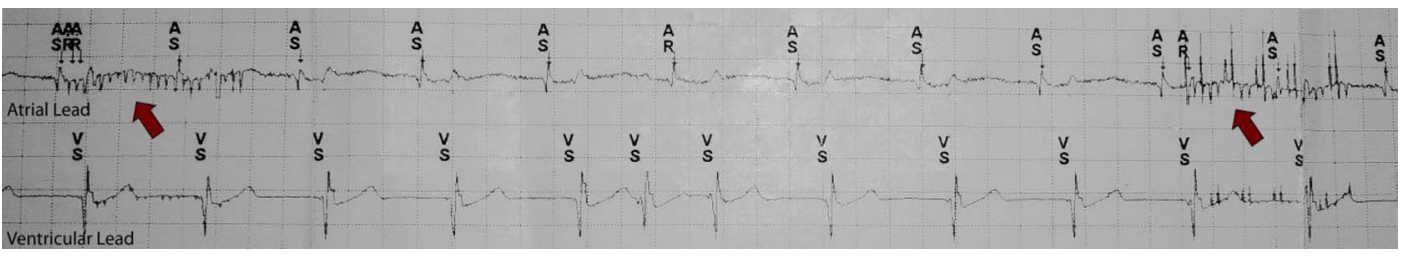

Figure 2 Repetitive bursts of diaphragmatic pacing shown as small oscillations (arrows) in the Medtronic Versa cardiac pacemaker, with no interference with atrial or ventricular sensing. Atrial pacing threshold: set at $0.750 \mathrm{v} /$ $0.40 \mathrm{~ms}$, ventricular pacing threshold: $0.750 \mathrm{v} / 0.40 \mathrm{~ms}$, P wave: $2.0 \mathrm{mv}$, R wave: $16.0 \mathrm{mv}$, atrial sensitivity setting: $0.50 \mathrm{mv}$, ventricular sensitivity setting: $5.6 \mathrm{mv}$ (AS, atrial sensed event; VS, ventricular sensed event). 
diaphragm paced repetitively at maximum output levels $(25 \mathrm{~mA})$. During DPS testing, the surface ECG demonstrated electrical interference shown as high-frequency oscillations (figure 1); however, interrogation of the cardiac pacemaker confirmed that, while there was evidence of electrical inference from repetitive diaphragmatic pacing, pacemaker function was unaffected (figure 2).

The surgery concluded successfully, and the patient is currently undergoing diaphragmatic conditioning. In line with earlier series, ${ }^{2}$ this case demonstrates that cardiac pacemakers are not a contraindication to the insertion of DPS provided appropriate testing is carried out intraoperatively.

Contributors LW and MN were the principle clinicians involved in managing of the patient. They both performed the literature review, photographed and prepared all the clinical images, and wrote the manuscript. KF and RLM assisted in the detailed literature review, in the preparation of all clinical images and the writing of the manuscript.

Competing interests None declared.

\section{Patient consent Obtained.}

Provenance and peer review Not commissioned; externally peer reviewed.

\section{REFERENCES}

1 Nagamoto $Y$, Shiomi T, Matsuura T, et al. Ventricular pacing inhibition by oversensing due to diaphragmatic myopotential during deep inspiration. J Cardiol Cases 2013;8: e81-4.

2 Onders RP, Khansarinia S, Weiser T, et al. Multicenter analysis of diaphragm pacing in tetraplegics with cardiac pacemakers: positive implications for ventilator weaning in intensive care units. Surgery 2010;148:893-7; discussion 897-8.

Copyright 2016 BMJ Publishing Group. All rights reserved. For permission to reuse any of this content visit http://group.bmj.com/group/rights-licensing/permissions.

BMJ Case Report Fellows may re-use this article for personal use and teaching without any further permission.

Become a Fellow of BMJ Case Reports today and you can:

- Submit as many cases as you like

- Enjoy fast sympathetic peer review and rapid publication of accepted articles

- Access all the published articles

- Re-use any of the published material for personal use and teaching without further permission

For information on Institutional Fellowships contact consortiasales@bmjgroup.com

Visit casereports.bmj.com for more articles like this and to become a Fellow 